\title{
ADVERTISING ON FOOD CHOICE: A STUDY OF BANK WORKERS IN GHANA
}

\author{
Daniel Edem Adzovie, Eunice Eshun, Philip Arthur Gborsong
}

\begin{abstract}
The study examined the influence advertising has on food choice of bank workers in Ghana. Whereas, there is a lot of empirical study on the influence of advertising on food choice in other countries, little is known about the phenomenon in Ghana, especially the influence of advertising on workers' food choice. The Uses and Gratification theory served as the lens for the study. Adopting the descriptive research design, we surveyed 200 respondents (bank workers) from 20 banks in the Central Region of Ghana, using convenience sampling procedure. Categories of food include fast foods, snacks, and food served in restaurants. The findings revealed that Television had the greatest influence on the food choice of respondents, followed by Radio. Taste was the highest influencing factor regarding bank workers' food choice. It was recommended that food advertisers must pay more attention to taste as a strong selling point when advertising their products.
\end{abstract}

Keywords: advertising, food choice, taste, bank workers, media, Central Region, Ghana

\section{INTRODUCTION}

Consumers are exposed to a wide range of advertisements in different media everyday thereby making advertising, sales promotion and public relations essential mass-communication tools available to marketers. Advertising is a communication process, a marketing process, an economic and social process, a public relations process or an information and persuasion process (Kazmi \& Batra, 2009; Arens, 1996). From its functional perspectives Dunn and Barban (1987) view advertising, as a paid, non-personal communication through various media by business firms, non-profit organization, and individuals who are in some way identified in the advertising message and who hope to inform or persuade members of an audience. Morden (1991) is of the opinion that advertising is used to establish a basic awareness of the product or service in the mind of the potential customer and to build up knowledge about it. Numerous products, including food products are presented to customers as well as potential customers through advertising.

Food is an integral part of daily life. It has a powerful effect on the health and well-being of consumers. International Labour Organisation's (ILO, 2019) report asserts that poor diet on the job is costing countries around the world up to 20 per cent in lost productivity, either due to malnutrition that plagues some one billion people in developing countries or the excess weight and obesity afflicting an equal number mostly in industrialized economies. The report notes that poor nourishment at the workplace can reduce productivity up to 20 percent, and this is obviously, a worrying situation.

Food choices are determined by a variety of factors including social class, time, preferences, cultural practices, media influences, and family structure. These dimensions and their factors are not only very large in number but possess influence that is complex in nature. The role of advertising in workers' choice of food has long been recognized as a significant factor. While diet fads, local and organic food movements saturate popular culture, food advertising seems to flood the media. This, compounded by money and time according to Reyes (2010), leads to a difference in dietary habits across society. Generally, food choices are apparently a class issue 
because often, the least expensive food is, the least nutritious food is assumed to be, which according to Wright and Ransom (2005), leads to structural inequality in society. Devine et al. (2009), De Irala-Estevez et al. (2000) and Donkin et al. (2000) assert that while some workers may have the opportunity to make food choices, others do not even have the luxury to think about food choice because their main concern is if there is even going to be enough food to eat. According to Sizer and Whitney (2008), consumers today value convenience so highly that they are willing to spend over half of their food budget on meals that require little or no preparation. They regularly eat out, bring home ready-to-eat meals, or have food delivered to them. We are of the assumption that this trend is mainly influenced by the media which promotes such behaviours through advertisements and popular programs and movies, which leads us to the issue of exposure.

As opined by Caraher and Landon (2006), exposure to food advertisement is one of the powerful forces driving the relationship between screen time and obesity. According to Denton (2013), food is an important factor in the proper or improper functioning of the body. Eating the wrong food can make people become overweight, undernourished, and at risk for the development of diseases and conditions, such as arthritis, diabetes, and heart disease. Duffey (2013), Batada et al. (2008) and Karupaiah et al. (2008) assert that people are swamped with advertisements which tend to promote unhealthy foods and beverages. More specifically, exposure to advertising may alter people's food intake. According to Johnson and CobbWalgren (1994) and Kelly et al. (2011), television advertising remains the primary channel through which companies reach consumers. According to Lazzari and Seidel (2019), predominantly, television advertising is used to influence viewers' buying decisions. Encouragingly, a study by Duffey (2013) states that advertisements and key product placement can influence a person's preference for and consumption of healthier food items. Howard (2018) asserts that on the average, an estimated $36.6 \%$ or approximately 84.8 million adults in the United States of America consume fast foods.

Consumers make many product decisions every day based on their interests or desires as well as suggestions from others (Evans, Jamal \& Foxall, 2009; Grunert, 2006). Advertisements make people aware of the products in the market. People are exposed to advertisements through billboards, television, product packaging and other media. According to Cheung et al. (2003) two factors that explain online consumer behaviour are: (1) consumer characteristics, including behavioural characteristics (looking for product information, access location, duration and frequency of usage) and experience; (2) environmental influences, like social, peer and mass media influences, which play important roles in affecting consumers' purchasing decisions. There is a significant gap in scientific inquiry into advertising and its relationship with food choice of workers in Ghana. With the underlying assumption that advertising plays a significant role in influencing the food choice of workers and since research on the subject matter is scanty in Ghana, the present study is deemed necessary.

Gender in advertising has been studied by scholars globally. Kappele (2015), Brooks and Hébert (2006), and Gerbner (1993) found forms of sexism in the way gender, regarding females are represented in the media, especially, in advertisements. Manippa et al. (2017) studied gender differences regarding food choice and found that generally, males preferred low calorie foods than females. Rickett (2014) and Wardle et al. (2004) opines assert that advertisers still use stereotypical stands in advertising, since food advertisements target women by exploring the taste factor while stressing less on calories. The purpose of the study is to assess the relationship between the nature of food advertisements on one hand and their relationship with the choice of food of bank workers in the Central Region of Ghana on another hand. It is also aimed at finding the nature of advertisement as well as the motivation behind the food choices of bank workers in the Central Region of Ghana. 
The study was directed by research questions and hypotheses. The following research questions were formulated: (1) What is the perception of bank workers in the Central Region of Ghana on the influence of advertising on their food choices?; (2) How frequent do bank workers in the Central Region of Ghana patronise fast foods? The following Hypotheses were tested: (1) There are significant gender differences in the advertising medium that influences bank workers' food choice in the Central Region of Ghana; (2) There is no significant gender difference in the factors that motivate bank workers in Central Region of Ghana to make their food choices.

The study is organised into four main areas. First, the theoretical framework that guides the study is discussed, followed by the method used to achieve the results. Thirdly, the results and discussion section is presented followed by the conclusions and recommendations.

\section{THEORETICAL FRAMEWORK}

From the perspective of the functionalist regarding mass communication, the Uses and Gratification (U\&G) theory originated. The pioneering rights of Uses and Gratification theory can be attributed to Katz, Blumler and Gurevitch in 1974. According to Ruggiero (2000), U\&G may be characterized by an inductive method for developing the nomenclature of different motivations and functions of media use. Basically, the assumption of $U \& G$ is that people are actively involved in the use of media for their purposes, and these people have high interactions with the communication media by building profile groupings of related uses and theoretically associated gratifications (Luo, 2002). The theory traces why consumers use media and what functions that media serves for them (Katerattanakul, 2002). According to McQuail (2010), initially, U\&G was developed in research on the effectiveness and efficiency of radio in the 1940s. The focus of U\&G is mainly on the explanations for the motivations and associated behaviours of audience members.

Scholars have employed U\&G to their studies. Example, Weiyan (2015) explores how U\&G variables affect audience satisfaction Internet Protocol Television (IPTV) and asserts that the introduction of computer-mediated communication has given new life to the significance of uses and gratifications theory. Hedstrom (2014) examines media use and diet by employing uses and gratification theory, when he tested and quantified moderating effects of emotional eating on the interaction between emotional needs and media use and finds significant effects of emotional eating. Klimsa (2010), in a study to bring clarity on the motives, attitudes, and obtained gratifications that people derive from online advertisements found that the meeting point of uses and gratifications theory and online marketing leads to profitability. Luo (2002) also finds that the perception of the web by Internet users as entertaining and informative generally show a positive attitude toward the Internet. In order to examine the relationship between advertisements (radio, TV, etc.) and workers' food choice, Uses and Gratification theory is appropriate.

\section{METHOD}

We adopted the descriptive research design. The population comprised bank workers specifically from the banks in the major towns and cities within the Central Region of Ghana. A sample size of 200 respondents from 20 selected banks in the Central Region was used for the study. The simple random and convenience sampling procedures were used. The simple random sampling technique was used in selecting the banks. The respondents from these banks were selected using the convenience sampling technique. In using convenience sampling to select the respondents, we went to various banks and sought the consent of staff available to provide responses for the study. The main research instrument used was the 'Food Choice Survey', a questionnaire designed by the researchers. The instrument was pilot tested on 20 
bank workers in the Greater-Accra Region of Ghana because they have similar characteristics with those in the Central Region. Reliability was established using the Cronbach Alpha reliability coefficient. Reliability of the instrument was undertaken to find out the precision, consistency and stability of a score from the instrument. The overall reliability coefficient from the pilot test was .89 .

\subsection{Data Collection Procedure}

The questionnaires were hand-delivered to the respondents, who were briefed on how to respond to the items. Also, respondents were given the opportunity to ask questions to clarify issues they did not understand. The questionnaires were collected a week after they had been distributed. This was to ensure that the respondents had enough time to complete the questions.

\subsection{Data Analysis Procedure}

The information gathered in the study was analysed using SPSS statistics. Serial and code numbers were assigned to each item on the questionnaire for easy identification before scoring them. Frequencies and percentages were used to answer the research questions. The Hypotheses were tested using t-test analysis. Based on a three-point Likert type scale, the mean scores were categorised as follows: Agree - 1.0-1.5; Disagree - 1.6-2.0; Not sure - 2.1-2.6. As such a mean of 1.5 and below shows that respondents strongly agreed with the item.

\section{RESULTS AND DISCUSSION}

This section presents the results of the study and discusses the findings from the data collected. The discussion is done under the various research questions and hypotheses.

\section{RQ 1: What is the perception of bank workers in the Central Region of Ghana on the influence of advertising on their food choices?}

Tab. 1 - Perception of Bank Workers on Influence of Advertising on their Food Choices. Source: own research

\begin{tabular}{|l|c|c|c|c|c|c|}
\hline Statement & $\begin{array}{c}\text { Agree } \\
\text { Frequency }\end{array}$ & $\%$ & $\begin{array}{c}\text { Disagree } \\
\text { Frequency }\end{array}$ & $\%$ & $\begin{array}{c}\text { Not Sure } \\
\text { Frequency }\end{array}$ & $\%$ \\
\hline Adverts make me eat healthy foods & 33 & 16.5 & 167 & 83.5 & - & - \\
\hline Adverts make me eat unhealthy foods & 46 & 23 & 145 & 72.5 & 9 & 4.5 \\
\hline Adverts influence my food choices & 18 & 9 & 174 & 87 & 8 & 4 \\
\hline $\begin{array}{l}\text { Without adverts, I will not be able to make } \\
\text { good food choices }\end{array}$ & 22 & 11 & 178 & 89 & - & - \\
\hline $\begin{array}{l}\text { The main determinant of my food choice is } \\
\text { advertisement }\end{array}$ & 6 & 3 & 194 & 97 & - & - \\
\hline $\begin{array}{l}\text { My food preferences are based on } \\
\text { advertisements }\end{array}$ & 7 & 3.5 & 193 & 96.5 & - & - \\
\hline $\begin{array}{l}\text { Television advertisements have strong } \\
\text { influences on my food choices }\end{array}$ & 104 & 52 & 96 & 48 & - & - \\
\hline Newspaper adverts affect my food choice & 81 & 40.5 & 113 & 56.5 & 6 & 3 \\
\hline $\begin{array}{l}\text { I would eat healthy whether there are adverts } \\
\text { on foods or not }\end{array}$ & 192 & 96 & 8 & 4 & - & - \\
\hline
\end{tabular}

Table 1 shows that more than half of respondents (174 out of 200) representing 87\% expressed the view that advertisements do not influence their choice of food. Also, 167 respondents, representing $83.5 \%$ disagree that advertisements influence their healthy eating. This finding is in sharp contrast to Duffey (2013), which indicated that advertisements influence a person's preference for and consumption of food items. This sharp contrast could probably be so, since Duffey's study considered a target group (children) that is sharply different from the group our study considered. Also, we observed that all the 20 banks sampled had television sets fitted in 
the banking halls. This may have contributed to the reason why a slight majority (104) agreed that they are influenced by television advertisements, since they are exposed to advertisements on television at work. However, the finding confirms Johnson and Cobb-Walgren (1994) and Kelly et al. (2011), who found that television is the primary medium through which advertisers reach their target.

RQ 2: How frequent do bank workers in the Central Region of Ghana patronise fast foods?

Tab. 2 - Weekly Eating Frequency of Fast Food Meals. Source: own research

\begin{tabular}{|c|c|c|}
\hline Number of Times & Number of Respondents & Percentage \\
\hline None & 9 & 4.5 \\
\hline $1-3$ & 140 & 70.0 \\
\hline $4-6$ & 43 & 21.5 \\
\hline $7-10$ & 8 & 4.0 \\
\hline Total & $\mathbf{2 0 0}$ & $\mathbf{1 0 0}$ \\
\hline
\end{tabular}

Table 2 indicates that majority (70\%) of the respondents eat fast foods one to three times a week while $30 \%$ patronize fast foods four to six times weekly. Just five percent eat fast foods 7-10 times weekly. For the purpose of precision fast foods are characterized as quick, easily accessible and cheap alternatives to home-cooked meals. Even though respondents who patronise fast foods many times in a week are in the minority, those who eat fast foods four to six times in a week (43 out of 200) represent second highest figure. This could be attributed to the fact that this category of workers is largely, not influenced by advertisements regarding food choice. This finding is closely related to Howard (2018), who found that averagely, an estimated $36.6 \%$ or approximately 84.8 million adults consume fast food daily in the United States of America.

RH 1: H1: There are significant gender differences in the advertising medium that influences bank workers' food choice in the Central Region of Ghana.

Tab. 3 - t-test on Gender Differences and Advertising Media. Source: own research

\begin{tabular}{|c|c|c|c|c|c|c|c|}
\hline Media & Gender & $\mathrm{N}$ & Mean & S.D. & $\mathrm{t}$ & $\mathrm{df}$ & Sig. \\
\hline \multirow{2}{*}{ Television } & Male & 98 & 1.55 & .628 & \multirow{2}{*}{-.819} & 198 & \multirow{2}{*}{.290} \\
\hline & Female & 102 & 1.63 & .688 & & & \\
\hline \multirow{2}{*}{ Radio } & Male & 98 & 1.87 & .568 & \multirow{2}{*}{.179} & 198 & \multirow{2}{*}{.842} \\
\hline & Female & 102 & 1.85 & .570 & & & \\
\hline \multirow{2}{*}{ Internet } & Male & 98 & 1.83 & .381 & \multirow{2}{*}{-.908} & 198 & \multirow{2}{*}{.069} \\
\hline & Female & 102 & 1.87 & .335 & & & \\
\hline \multirow{2}{*}{ Billboard } & Male & 98 & 1.97 & .392 & \multirow{2}{*}{-1.564} & 198 & \multirow{2}{*}{.524} \\
\hline & Female & 102 & 2.05 & .326 & & & \\
\hline \multirow{2}{*}{ Magazine } & Male & 98 & 2.06 & .450 & \multirow{2}{*}{.043} & 198 & \multirow{2}{*}{.083} \\
\hline & Female & 102 & 2.06 & .340 & & & \\
\hline \multirow{2}{*}{ Newspaper } & Male & 98 & 1.94 & .241 & \multirow[t]{2}{*}{2.176} & 198 & \multirow{2}{*}{.000} \\
\hline & Female & 102 & 1.84 & .365 & & & \\
\hline
\end{tabular}

Table 3 presents the t-test results on gender differences and advertising media at an alpha level of 0.05 . Table 3 shows that there were no significant differences in five of the media (namely television, radio, internet, billboard and magazine). It can be observed that, regarding newspaper, there was a significant difference (.000) between males and females. As indicated earlier, a mean of 1.5 and below signals a more popular choice. The means show that majority of the respondents considered Television to be the medium that had the greatest influence on 
their food choice (1.51 for males and 1.48 for females). In order of the most influencers, Radio was the next preferred option, then Internet, Newspaper, Billboard and Magazine. On some of the items, the males had lower means than the females which showed they preferred the item relatively more than the females and vice versa. Males preferred Radio, Internet, Billboard and Magazine while females preferred Television and Newspaper. In general, Newspapers, Magazines and Billboards were reported to have the least influence on the choice of food of bank workers regardless of gender. In general, due to the result obtained, research hypothesis one is rejected.

To support the finding of television being the most influencing medium, Duffey (2013) noted that television advertising remains the primary channel through which companies reach consumers. This finding is also corroborated by Johnson and Cobb-Walgren (1994) and Kelly et al. (2011). We assume that television being audio-visual medium may be a contributing factor to this finding. This is because television audience would not only listen to sound as in Radio, but see visuals (both still and motion).

RH 2: H1: There are significant gender differences in the factors that motivate middle-
class workers' in Central Region of Ghana to make their food choices.

Tab. 4 - t-test on Gender Differences and Motivating Factors. Source: own research

\begin{tabular}{|c|c|c|c|c|c|c|c|}
\hline Motivating factor & Gender & $\mathrm{N}$ & Mean & S.D. & $\mathrm{t}$ & $\mathrm{df}$ & Sig. \\
\hline \multirow{2}{*}{ Convenience } & Male & 98 & 1.94 & .534 & \multirow{2}{*}{1.94} & 198 & \multirow{2}{*}{.840} \\
\hline & Female & 102 & 1.94 & .523 & & & \\
\hline \multirow{2}{*}{ Taste } & Male & 98 & 1.54 & .501 & \multirow{2}{*}{1.54} & 198 & \multirow{2}{*}{.618} \\
\hline & Female & 102 & 1.56 & .499 & & & \\
\hline \multirow{2}{*}{ Preference } & Male & 98 & 1.95 & .563 & \multirow{2}{*}{1.95} & 198 & \multirow{2}{*}{.802} \\
\hline & Female & 102 & 1.88 & .532 & & & \\
\hline \multirow{2}{*}{ Time } & Male & 98 & 1.96 & .555 & \multirow{2}{*}{1.96} & 198 & \multirow{2}{*}{.079} \\
\hline & Female & 102 & 1.97 & .455 & & & \\
\hline \multirow{2}{*}{ Money } & Male & 98 & 1.87 & .620 & \multirow{2}{*}{1.87} & 198 & \multirow{2}{*}{.523} \\
\hline & Female & 102 & 1.83 & .564 & & & \\
\hline \multirow{2}{*}{ Adverts } & Male & 98 & 2.06 & .450 & \multirow{2}{*}{2.06} & 198 & \multirow{2}{*}{.143} \\
\hline & Female & 102 & 2.02 & .398 & & & \\
\hline
\end{tabular}

Table 4 presents the results based on an independent samples t-test analysis at an alpha level of 0.05. Table 4 shows that there were significant gender differences regarding Preference, Time and Money. Also, majority of the respondents noted that "Taste" was the most influencing factor in determining their food choice (1.33 for males and 1.30 for females). In order of the most motivating factors, Money was the next, followed by Preference, Time, Convenience and Adverts. On most of the items, the females had lower means than the males which showed they preferred the item relatively more than the males. Females considered Taste, Preference, Time and Adverts as motivating more than the males. Regarding convenience both males and females had the same means. Due to the result obtained, hypothesis two is retained.

The finding of taste been the most influencing factor seems to confirm the European Food Information Council (IFIC, 2011) which noted that 'taste' is consistently reported as a major influence on food behaviour. A liking for sweetness and a dislike for bitterness are considered innate human traits, present from birth. 'Taste' is the sum of all sensory stimulation that is produced by the ingestion of a food. This includes not only taste per se but also smell, appearance and texture of food. These sensory aspects are thought to influence spontaneous food choice. Again, in relation to the finding that money was also a great influencing factor for 
food choice, the study confirms De Irala-Estevez et al. (2000), who reported that the cost of food is a primary determinant of food choice. Whether cost is prohibitive depends fundamentally on a person's income and socio-economic status. However, it must be noted that access to more money does not automatically equate to a better-quality diet but only increases the range of foods from which one can choose. Similarly, a survey by the International Food Information Council (IFIC, 2011) Foundation asked 1,000 Americans about their habits when it comes to food choices. Taste ranked number one for most (87\%), but price quickly caught up. In fact, the cost of food was said to be the fastest-growing determinant of food choice. In the study, $79 \%$ of people said price affects their food choices.

Supporting Preference and Time as motivating factors, Donkin et al. (2000), who identified time factor which includes accessibility to shops as an important physical factor influencing food choice. They further noted that it is dependent on resources such as transport and geographical location. Preference may be an important factor probably because it is dependent on taste of food (which is the most influencing factor).

Relatively, convenience and advertisements were reported to be the least influencing factors in the determination of the food choice of bank workers in the Central Region of Ghana. This finding is contrary to Sizer and Whitney (2008) who reported that consumers today value convenience so highly that they are willing to spend over half of their food budget on meals that require little or no preparation. They regularly eat out, bring home ready-to-eat meals, or have food delivered to them. This trend is mainly influenced by the media which promote such behaviours through commercials and popular programmes and movies. Grunert (2006), an American researcher noted that the most important aspect of marketing in the consumer's perspective is convenience. He further noted that the problem with these convenience foods, is that they are typically not nutritious in any way, shape, or form, and are usually high in fat, calories, and carbohydrates. This could probably be the reason why convenience is not a strong influencing factor identified by this study.

Regarding gender differences in making food choice, Wardle et al. (2004), in examining food choice behaviours among young adults found that women generally avoid fatty foods as compared to men. They also found that women paid more attention to healthy eating as compared to men.

\section{IMPLICATIONS}

The practical implication of the study is that advertisers as well as advertising practitioners, especially copywriters for food advertisements must pay more attention to taste when writing copies targeted at workers in Ghana, since taste proved to be the highest influencing factor. Also, Television proved to have the greatest influence on the food choice of bank workers in Ghana, hence media planners must be more strategic and consider placing food advertisements on television.

\section{CONCLUSIONS \& RECOMMENDATIONS}

We sought to examine the influence of advertising on food choice of bank workers in the Central Region of Ghana. Regarding theory, the study expands the frontiers of the Uses and Gratification theory by demonstrating how bank workers use media as well as advertising and its effect on bank workers' food choice in Ghana. With the busy nature of respondents (bank workers) sampled and the assumption that they would be easily influenced by advertisements in making their food choice, since they do not have the luxury of time to prepare their own meals, the findings reveal slightly otherwise. The findings of this study are revealing, although 
generalisation must be done with caution, since it was conducted in only one region out of the sixteen regions of Ghana. This notwithstanding, however, the findings apply to bank workers in Ghana. It is instructive to note that food advertisements have some influence, but minimal, on the food choice bank workers in Ghana. The next stage of our study will broaden the scope to capture all sixteen regions in Ghana, as well as include more variables such as Word of Mouth (WoM).

We recommend that advertisers and advertising executives must put more effort into their messaging strategy regarding food ads, by paying more attention to taste of food as well as cost of food in order to guarantee maximum impact of ads.

\section{References}

Arens, W. F. (1996). Contemporary advertising. New York: McGraw-Hill.

Batada, A., Seitz, M. D., Wootan, M. G., \& Story, M. (2008). Nine out of 10 food advertisements shown during Saturday morning children's television programming are for foods high in fat, sodium, or added sugars, or low in nutrients. Journal of the American Dietetic Association, 108(4), 673-678. doi: 10.1016/j.jada.2008.01.015

Brooks, D. E., \& Hébert, L. P. (2006). Gender, race, and media representation. In B. J. Dow \& J. T. Wood, The SAGE Handbook of Gender and Communication. London: SAGE. doi: 10.4135/9781412976053.n16

Caraher, M., \& Landon, J. (2006). The impact of advertising on food choice: The social context of advertising. In R. Shepherd \& M. Raats (eds.), The Psychology of Food Choice: Frontiers in nutritional science. Wallingford: CABI. doi: 10.1079/PHN2005879

Cheung, C. M. K., Zhu, L., Kwong, T., Chan, G. W. W., \& Moez, L. (2003) Online Consumer Behaviour: A Review and Agenda for Future Research. Paper presented at The 16th Bled eCommerce Conference eTransformation, Bled, Slovenia. Retrieved from https://aisel.aisnet.org/cgi/viewcontent.cgi?article=1112\&context=bled2003

De Irala-Estevez, J., Groth, M., Johansson, L., Oltersdorf, U., Prättälä, R., \& MartínezGonzález, M. A. (2000). A systematic review of socio-economic differences in food habits in Europe: consumption of fruit and vegetables. European journal of clinical nutrition, 54(9), 706-714. doi: 10.1038/sj.ejcn.1601080

Denton, C. L. N. (2013). How does food impact health. Regents of the University of Minnesota. Retrieved from http://www.takingcharge.csh.umn.edu/explore-healing-practices/foodmedicine/how-does-food-impact-health

Devine, C. M., Farrell, T., Blake, C. E., Jastran, M., Wethington, E., \& Bisogni, C. A. (2009). Work Conditions and the Food Choice Coping Strategies of Employed Parents. Journal of Nutrition Education and Behaviour, 41(5), 365-370. doi: 10.1016/j.jneb.2009.01.007

Donkin, A. J., Dowler, E. A., Stevenson, S. J., \& Turner, S. A. (2000). Mapping access to food in a deprived area: The development of price and availability indices. Public Health Nutrition, 3(1), 31-38. doi: 10.1017/s1368980000000057

Duffey, K. (2013). Food on the brain: How advertising can influence your child's diet. Retrieved from www.ourregularlyscheduledprogram.com

Dunn, S. W., \& Barban, A. (1987). Advertising, it's role in modern marketing advertising. Hindsdale: Dryden Press.

Evans, M., Jamal, A., \& Foxall, G., (2009). Consumer behaviour. Ney York: Wiley. 
Gerbner, G. (1993). Women and minorities on television: A study in casting and fate. Philadelphia: University of Pennsylvania.

Grunert, K. G. (2006). Marketing parameters and their influence on consumer food choice. Wallingford: CABI.

Hedstrom, A. E. (2014). Media use and diet: A dynamic uses and gratifications approach. Columbus: The Ohio State University.

Howard, J. (2018). Here's how much fast food Americans are eating. Retrieved from https://edition.cnn.com/2018/10/03/health/fast-food-consumption-cdcstudy/index.html

IFIC (2011). International Food Information Council Foundation Releases Its 2011 Food \& Health Survey. Retrieved from https://foodinsight.org/international-food-informationcouncil-foundation-releases-its-2011-food-health-survey/

ILO (2019). Poor workplace nutrition hits workers' health and productivity. Retrieved from https://www.ilo.org/global/about-the-ilo/newsroom/news/WCMS_005175/lang-en/index.htm

Johnson, R. L., \& Cobb-Walgren, C. J. (1994). Aging and the problem of television clutter. Journal of Advertising Research, 34(4), 54-63. Retrieved from https://psycnet.apa.org/record/1995-23466-001

Katerattanakul, P. (2002). Framework of effective web site design for business-to-consumer internet commerce. INFOR: Information Systems and Operational Research, 40(1), 57 70. doi: 10.1080/03155986.2002.11732641

Karupaiah, T., Chinna, K., Mee, L. H., Mei, L. S., \& Noor, M. I. (2008). What's on Malaysian television? A survey on food advertising targeting children. Asia Pacific Journal of Clinical Nutrition, 17(3), $71 \quad$ - 84. Retrieved from https://www.researchgate.net/publication/23281734_What's_on_Malaysian_Televisio n_-_A_survey_on_food_advertising_targeting_children

Kappele, A. E. (2015). The role of gender representations on craft beer labels. Columbia: University of Missouri.

Kazmi, S. H. H., \& Batra, S. K. (2009). Advertising and Sales Promotion. New Delhi: Excel Books.

Kelly, B., Chapman, K., King, L., \& Hebden, L. (2011). Trends in food advertising to children on free-to-air television in Australia. Australian and New Zealand journal of public health, 35(2), 131-134. doi: 10.1111/j.1753-6405.2011.00612.x

Klimsa, P. (2010). Uses and gratifications of online advertising. Ilmenau: Technical University.

Lazzari, Z. \& Seidel, M. (2019). The Influence of television advertising. Retrieved from https://smallbusiness.chron.com/influence-television-advertising-64010.html

Luo, X. (2002). Uses and gratifications theory and e-consumer behaviors: a structural equation modeling study. Journal of Interactive advertising, 2(2), 34-41. doi: $10.1080 / 15252019.2002 .10722060$

Manippa, V., Padulo, C., van der Laan, L. N., \& Brancucci, A. (2017). Gender differences in food choice: effects of superior temporal sulcus stimulation. Frontiers in human neuroscience, 11, 597. doi: 10.3389/fnhum.2017.00597

McQuail, D. (2010). McQuail's mass communication theory. London: SAGE. 
Morden, A. R. (1991). Elements of marketing. London: D.P. Publication.

Reyes, A. M. (2010). Influences on college students' eating habits. Tucson: University of Arizona.

Rickett, O. (2014). Food advertising is still feeding gender stereotypes. Retrieved from https://www.vice.com/en_us/article/d75nvk/food-advertising-is-still-feeding-genderstereotypes

Ruggiero, T. E. (2000). Uses and gratifications theory in the 21st century. Mass communication \& society, 3(1), 3-37. doi: 10.1080/08838151.2013.845827

Sizer, F. S \& Whitney, E. (2008). Nutrition: Concepts and controversies. Boston: Cengage Learning.

Wardle, J., Haase, A. M., Steptoe, A., Nillapun, M., Jonwutiwes, K., \& Bellisie, F. (2004). Gender differences in food choice: the contribution of health beliefs and dieting. Annals of behavioural medicine, 27(2), 107-116. doi: 10.1207/s15324796abm2702_5

Weiyan, L. I. U. (2015). A historical overview of uses and gratifications theory. Cross-Cultural Communication, 11(9), 71-78. doi: 10.3968/7415

Wright, W., \& Ransom, E. (2005). Stratification on the menu: Using restaurant menus to examine social class. Teaching Sociology, 33(3), 310-316. doi: $10.1177 / 0092055 \times 0503300311$

\section{Contact information}

\section{Daniel Edem Adzovie}

Tomas Bata University in Zlín, Faculty of Multimedia Communications

Univerzitní 2431, 76001, Zlín, Czech Republic

E-mail: adzovie@utb.cz

ORCID: 0000-0001-5553-5705

\section{Eunice Eshun}

University of Cape Coast, Faculty of Arts

Cape Coast, Ghana

E-mail: eunice.eshun@ucc.edu.gh

ORCID: 0000-0001-6146-3306

\section{Prof. Philip Arthur Gborsong}

University of Cape Coast, Faculty of Arts

Cape Coast, Ghana

E-mail: pgborsong@ucc.edu.gh

ORCID: 0000-0003-1819-7844

doi: 10.7441/dokbat.2019.001 